\title{
ASTER AND WORLDVIEW-2 SATELLITE DATA COMPARISON FOR IDENTIFICATION OF GROUNDWATER SALINIZATION EFFECTS ON THE CLASSE PINE FOREST VEGETATION (RAVENNA, ITALY)
}

\author{
M. Barbarella ${ }^{\mathrm{a}}$, M. De Giglio ${ }^{\mathrm{a}, *}$, N. Greggio ${ }^{\mathrm{b}}$, L. Panciroli $^{\mathrm{a}}$ \\ ${ }^{a}$ Civil, Chemical, Environmental and Materials Engineering Department (DICAM), University of Bologna, Viale Risorgimento 2, \\ 40136 Bologna, Italy - maurizio.barbarella@unibo.it, michaela.degiglio@unibo.it, lorenzo.panciroli@studio.unibo.it \\ ${ }^{\mathrm{b}}$ Interdepartmental Centre for Environmental Science Research (CIRSA), Lab. IGRG, University of Bologna, Via S. Alberto 163, \\ 48100 Ravenna, Italy - nicolas.greggio2@unibo.it
}

BIOD-8

KEY WORDS: Aster, WorldView - 2, NDVI, stressed vegetation, groundwater salinity

\begin{abstract}
:
The availability of a large number of data acquired by satellite sensors with different spatial and spectral resolutions has always required an evaluation of their synergistic use. The integration of dataset of images coming from different sources can be an optimal solution for the study of various environmental problems which need a continuous monitoring (coastal development, forest evolution, land use changes etc.). The Classe pinewood, an important safeguarded biodiversity hot spot near Ravenna city (Italy), is historically affected by the groundwater salinization. Since changes in the water concentration are able to induce variations of the leaf properties and vegetation cover, recognizable by surveys carried out with different spectral bands, the comparison between ASTER and Worldview-2 data was performed using the (Normalized Difference Vegetation Index) NDVI. For each satellite data, the same Areas of Interest (AOIs) were selected within the most widespread cover, Thermophilic Deciduous Forest (TDF). The NDVI was calculated, statistically evaluated and the AOI rankings were built. In order to evaluate the difference between the results provided by the two images, statistical tests were applied on the average NDVI values. Finally the calculated NDVI were compared with groundwater salinity data collected during a contemporary field monitoring campaign. Based on groundwater salinity the same AOIs ranking was reached for both satellite sensors. This study suggests the opportunity to employ the medium resolution Aster images in continuity with high resolution WarldView-2 dataset.
\end{abstract}

\subsection{INTRODUCTION}

The availability of a constantly increasing number of satellites observing the Earth (Bailey et al., 2001) require tools and procedures to integrate the results obtained from data with different spectral and spatial resolutions (Wald et al., 1997; Chander et al., 2008). The main purpose is to achieve the continuity of data by temporal infill for the monitoring and modelling of natural resources (Yin et al., 2012). In fact, the use of data from different sensors can maximize the chances of obtaining a cloud-free image and to meet time requirements for information. In particular, several studies reported the intercomparison of the Normalized Difference Vegetation Index (NDVI) data (Thenkabail, 2004; Abuzar et al., 2014).

Many researchers used the NDVI as a biophysical indicator to analyze indirect effects of environmental changes (Aguilar et al. 2012; Barton, 2012), including those due to processes of salinization (Naumann et al. 2008; Zhang et al. 2011). The delineation of type and status of vegetation could provide a spatial overview of salinity distribution (Dehaan and Taylor, 2002; Tilley et al. 2007) and support land planners to reduce the risk resulting from salinization (Wiegand et al. 1994). Increased water salinity induces changes in chlorophyll concentration and therefore a photosynthesis slowdown (DeLaune et al. 1987). By measuring the relative difference between responses of chlorophyll and cellular structure in the red and near-infrared bands (Peñuelas, 1998), the NDVI analyses the greenness and al. productivity (Reed et 1994) of the plants.
The roman-time Classe pinewood (Ravenna, Italy), selected as study area, has been affected by groundwater salinization for several years (Antonellini et al. 2008). Included in the Po Delta Park, with other natural features of this region (wetlands, dunes, river mouths), it is classified as a protected area (EU site of importance and special area of conservation), in conformity with the Council Directive 92/43/EEC (http://ec.europa.eu/environment/nature/legislation/habitatsdirec tive/). Here, natural and anthropogenic land subsidence, low topography and the artificial drainage system led to a widespread saltwater intrusion (Antonellini et al. 2008). Antonellini and Mollema (2010) found that groundwater salinity and the water table level are the main causes of a progressive degradation of this ancient pine forest and of the coastal zones. Furthermore, according to the results of Giorgi and Lionello (2008), climate change will have a large influence on the water budget of Mediterranean countries, leading to an increase in the dry periods and to a subsequent increase of sea water intrusion.

Therefore, in order to monitor the temporal evolution of the pine forest health status and groundwater quality an upgradable dataset is necessary. Furthermore, the availability of comparable data from different sensors would provide comprehensive and continuous information over time. In this work, a comparison between two multispectral satellite data has been conducted with the aim to assess their potential integrated use. The presented analysis is based on ASTER and Worldview-2 (below WV-2) images, acquired in May 2011. In order to study the possible advantages of high spatial resolution in face of the

* Corresponding author. Michaela De Giglio, DICAM - University of Bologna, Viale Risorgimento 2, 40136 Bologna (Italy), Phone: +39 0512093109, Fax: +39 0512093114, michaela.degiglio@unibo.it. 
medium resolution, the same procedure to identify portions of pinewood affected by groundwater salinization (Barbarella et al., 2015) was applied to each satellite data and the results were statistically compared (Pu and Landry, 2012). Given that, within the Classe pinewood, the same stressed areas were recognized, this study can suggest the use of the medium resolution in continuity with high resolution dataset.

\section{STUDY AREA}

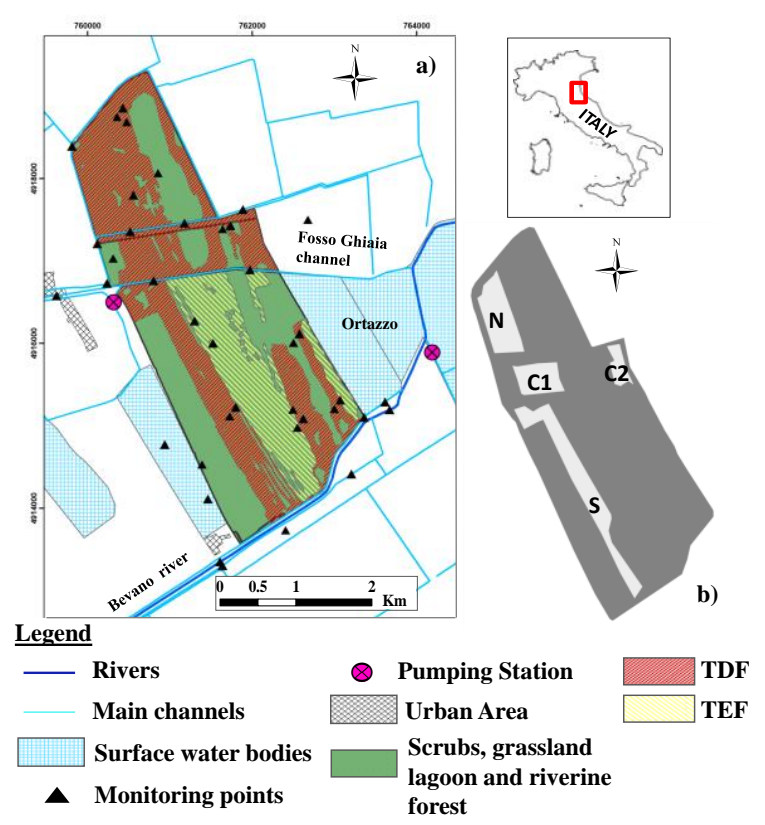

Figure 1. Classe pinewood (a) and the Areas of Interest (b)

The historical Classe pinewood (Fig. 1 (a)), included in the Po Delta Regional Park (Ravenna, Italy) because of its considerable plant and animal biodiversity, is $5 \mathrm{~km}$ long and 2 $\mathrm{km}$ large (900 ha). The pine forest is mainly surrounded by agricultural land except for the South-East part where it borders with the Ortazzo freshwater lagoon. The thickness of the underlying aquifer varies from a minimum of 6 to a maximum of $22 \mathrm{~m}$ (Amorosi et al. 1999).

Because of the low topography (about $2 \mathrm{~m}$ amsl) the area is strongly drained and a pumping station is present in the western part of the pinewood. Furthermore, the Bevano River and Fosso Ghiaia channel flow respectively in the southern boundary and in the center of the pinewood. Those two channels are directly open to the sea and especially during drought period, seawater can encroach the riverbed and reach the pineforest (Antonellini et al. 2008).

Based on the official vegetation map from Regione Emilia Romagna (1999), two main vegetation types are present in the Classe pineforest: "Thermophilic Deciduous Forest" (below TDF) and "Thermophilic Evergreen Forest" (below TEF). The main species found in both classes are Quercus robur, Quercus pubescens, Fraxinus ornus, Populus alba, Ulmus minor, Salix cinerea. The only difference between TDF and TEF is the presence of Quercus ilex (evergreen species) which indicates a drier and more elevated habitat. Because of its wider extension the TDF was selected as the target vegetation in this study. The Pinus pinea species is not classified in the vegetation map because it is not able to reproduce itself inside these natural area. Moreover this species, planted by monks in the 13th AD
(Ginanni, 1774), is stressed because it grows outside of its original climax (Piccoli et al. 1991).

\section{METHODS}

Before comparing the ASTER (VNIR sensor only, spatial resolution of $15 \mathrm{~m}$ ) and the $\mathrm{WV}-2$ data (spatial resolution of $2 \mathrm{~m}$ ), the procedure developed on the nearby San Vitale Pinewood (Barbarella et al., 2015) was applied to each satellite data. Since the two images were acquired respectively on 05/18/2011 and on 05/29/2011, the atmospheric correction to retrieve surface reflectance was required (Yuan and Niu 2008, Abuzar et al., 2014). This pre-processing step was performed by the MODTRAN4 module as implemented into ENVI FLAASH (FLAASH Module, 2009).

For both ASTER and WV-2 images, the NDVI was calculated with ENVI software (below NDVI_A11 and NDVI_W11 respectively) for the same four Areas of Interest (AOIs, Fig. 1(b)), selected inside the TDF class (N, C1, C2, S). For each AOI, the NDVI values were statistically evaluated (mean, standard deviation). In order to understand if the difference between results provided by the two satellite data was significant, a statistical test was applied on the average NDVI values. In this case, considering that the two unknown population variances are not assumed to be equal, the Student's t-test (Eq. 1) was used to verify whether the population means were different, based on the statistic:

$$
t=\frac{\left(\bar{x}_{1}-\bar{x}_{2}\right)}{\sqrt{\frac{s_{1}^{2}}{n_{1}}+\frac{s_{2}^{2}}{n_{2}}}}
$$

where $\bar{x}_{1}, \bar{x}_{2}, s_{1}^{2}, s_{2}^{2}=$ population means and variances,

$$
\mathrm{n}_{1}, \mathrm{n}_{2}=\text { number of pixel }
$$

and for the degree of freedom $(v)$ computation the Welch formula was used

$$
v \approx=\frac{\left(\frac{s_{1}^{2}}{n_{1}}+\frac{s_{2}^{2}}{n_{2}}\right)^{2}}{\left(\frac{s_{1}^{2}}{n_{1}}\right)^{2} /\left(n_{1}-1\right)+\left(\frac{s_{2}^{2}}{n_{2}}\right)^{2} /\left(n_{2}-1\right)}
$$

Subsequently, the frequency histograms of AOI NDVI values were plotted to explain the data distributions and higher order moments, Skewness and Kurtosis shape factors, were obtained to evaluate a possible deviation from the Guassian trend. In every image, using the AOI with the highest average NDVI, the NDVI value corresponding to the $5 \%$ of the pixels was used as threshold to compare the health vegetation status. Later, the percentages of pixels that fall below this limit were classified as stressed vegetation in all the other AOIs. Finally, the AOI rankings for each satellite image was carried out (Steps shown in the right column of flow chart., Fig 2).

In order to compare the results obtained from the two different sensors, further phases have been added to the original procedure (Steps shown in the left column of flow chart, Fig 2). The first analysis consisted in the statistical comparison of the average NDVI values for each AOI.

Afterwards, to compare the two satellite data at the same spatial resolution, the WV-2 pixels (2m) were resampled and reprojected to the ASTER projection and pixel size $(15 \mathrm{~m})$. Based on the same AOIs the statistical NDVI analysis were repeated. The availability of NDVI values comparable for all pixels 
allowed to assess the correlation pixel by pixel between the two images.

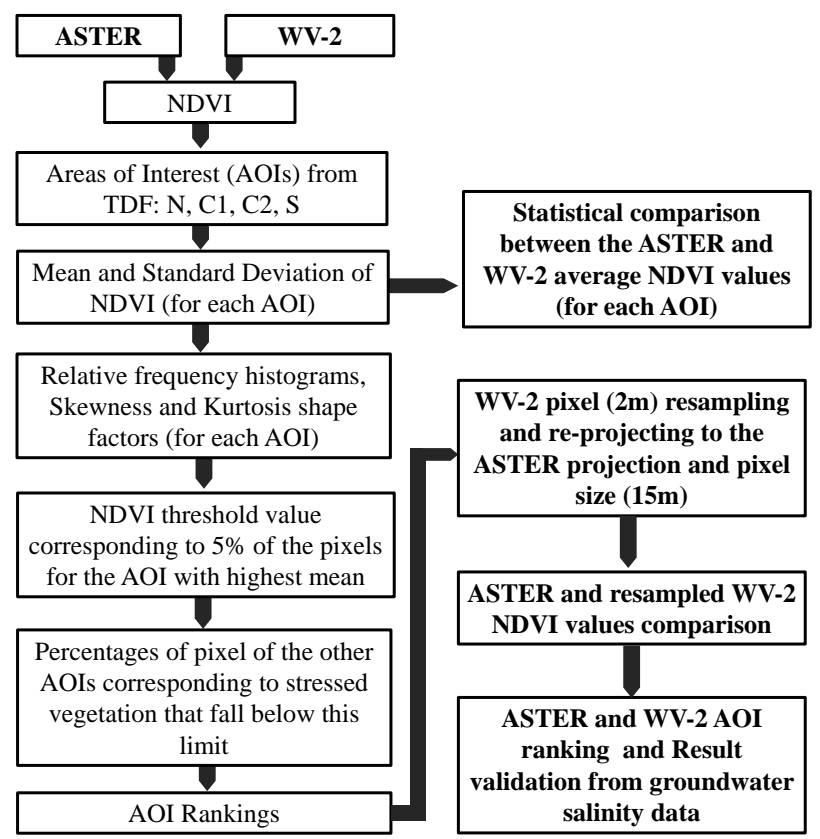

Figure 2. Flow chart of the whole procedure used to compare ASTER and WV-2 data

Finally, to validate the ASTER and WV-2 ranking salinity data collected from contemporary groundwater monitoring campaign were used.

During the Spring 2011, electrical conductivity and water table depth measures were collected within and surrounding the Classe pine forest from shallow piezometers (10 locations), surface water bodies (16 locations) and drainage channels (13 locations), (Fig. 1(a)). Electrical conductivity was converted into salinity using UNESCO methodology (1983) while water table depth was referred to the mean sea level. In order to produce the salinity maps only the top aquifer salinity were used. Firstly because of its contact with the trees roots and secondly because of its role in the supply of water during the evaporation processes (Buscaroli and Zannoni, 2010).

An interpolated grid was created for the month corresponding to the image acquisition dates (May 2011). Starting from sparse points, the Kriging algorithm with linear variogram was applied to obtain a continuous pattern (Akkala et al. 2010) using the software SURFER 11. The spacing of nodes is identical to the geometric resolutions of the satellite data. The saline contour line maps were overlaid with the AOIs location to highlight zones of pinewood affected by saltwater intrusion. Later from the original grid file, salinity values were extracted for each node within the AOIs boundaries. After this, means, standard deviations, minimums and maximums were computed for every area. Thus, the relation between NDVI and groundwater salinity data was analysed for each image. To study the relationship between the average NDVI (Y) and salinity (X) values, the errors that affect both variables must be considered. Therefore, assessing the linear fit, the use of the traditional formulas that consider the independent variable $(\mathrm{X})$ as error-free was not correct. Accordingly, in this study, the following regression model was applied. The linear function:

$Y=\alpha+\beta X$

has been combined with a more complex statistical model.
For a generic point it was possible to consider that the value of the coordinate measured was affected by a normally distributed error, i.e. $\tilde{\mathrm{x}}_{\mathrm{k}}=\mathrm{X}_{\mathrm{k}}+\varepsilon_{\mathrm{Xk}}$ and $\tilde{\mathrm{y}}_{\mathrm{k}}=\mathrm{Y}_{\mathrm{k}}+\varepsilon_{\mathrm{Yk}}$, where $\varepsilon_{\mathrm{k}} \in N\left(0, \sigma_{\varepsilon \mathrm{k}}{ }^{2}\right)$, $\eta_{\mathrm{k}} \in N\left(0, \sigma_{\eta \mathrm{k}}^{2}\right), \operatorname{cov}\left(\varepsilon_{\mathrm{i}}, \eta_{\mathrm{j}}\right)=0$ with $i, j, k=1,2, . . n$.

Substituting each unknown regression parameter with an approximate value and an unknown correction, $\alpha=a_{0}+\delta a, \beta=b_{0}+\delta b$, and , eliminating the infinitesimal of higher order $\delta b v_{x}$, the linear function became

$\left.\left[\begin{array}{ll}1 & x_{k}\end{array}\right]\left[\begin{array}{l}\delta a \\ \delta b\end{array}\right]+\left[\begin{array}{ll}b_{o} & -1\end{array}\right] \mid \begin{array}{l}v_{x_{k}} \\ v_{y_{k}}\end{array}\right\rfloor+a_{o}+b_{o} x_{k}-y_{k}=0$

with $\mathrm{k}=1,2, . . \mathrm{n}$.

For all points the functional model was:

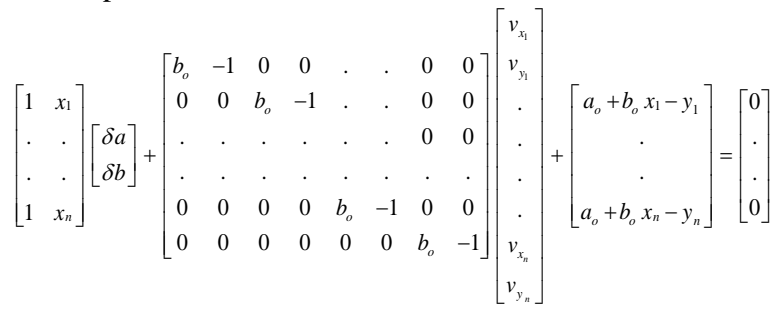

That is:

$\underset{n^{* 2}}{B} \underset{2^{* 1}}{\underline{u}}+\underset{n^{* 2 \mathrm{n}}}{A} \underset{2 \mathrm{n}^{* 1}}{\underline{v}}+\frac{f}{n^{* 1}}=\underline{\underline{0}}$

with the associated stochastic model

$\Sigma_{f f}=\operatorname{diag}\left(\sigma_{x_{1}}^{2}, \sigma_{y_{1}}^{2}, \ldots, \sigma_{x_{n}}^{2}, \sigma_{y_{n}}^{2}\right) \equiv \sigma_{o}^{2} Q_{f f}$

The model solution obtained by applying the method of weighed least squares was:

$\left.\delta \underline{u}=-B^{t}\left(A Q_{l} A^{t}\right)^{-1} B\right]^{-1} B^{t}\left(A Q_{l} A^{t}\right)^{-1} \underline{f}$

with the cofactor matrix of the unknowns given by

$Q_{\delta u}=\left[B^{t}\left(A Q_{l} A^{t}\right)^{-1} B\right]^{-1}$

To initialize the interactive process, the fit according to traditional formulas was considered while the end of the iteration criterion was based on the negligible increase of the estimated parameters.

\section{RESULTS AND DISCUSSION}

The result section is divided into three subparagraphs: ASTER and WV-2 comparison; ASTER and resampled WV-2 comparison and the finding validation by groundwater salinity data.

\subsection{ASTER and WV-2 comparison}

The NDVI results relative to ASTER and WV-2 images are reported as a map in figure 3 . It is possible to see, according to the chromatic scale, an apparent improvement in the NDVI_W11. This last aspect could be related to the mediation of the reflectance value assigned to the Aster pixel corresponding to a larger area on the ground compared to the pixel of the WV-2. 


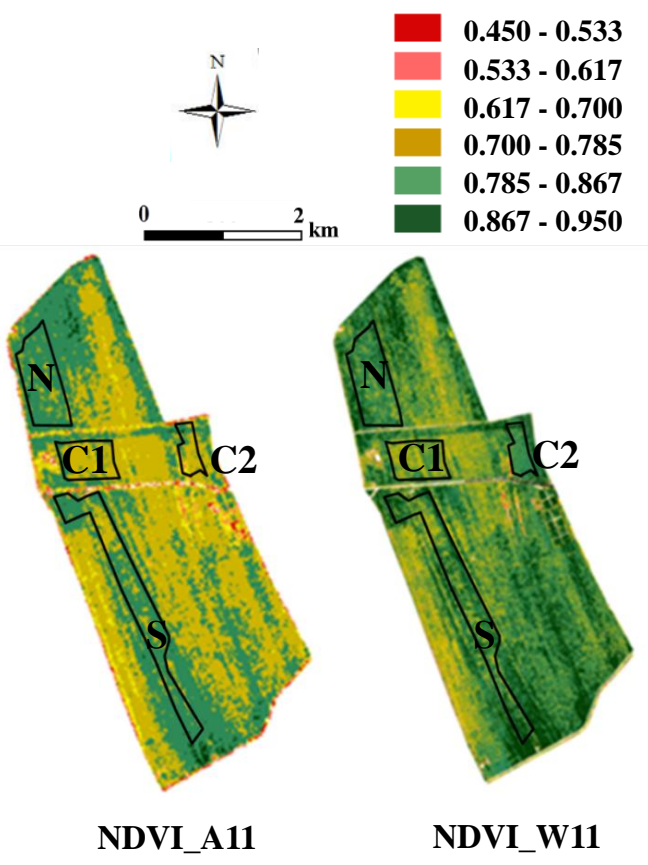

Figure 3. Classe NDVI maps

For each AOI, the mean and the standard deviation of vegetation index values are shown in table 1 . Within the same scene the four AOIs are statistically separated. In each satellite data, $\mathrm{N}$ and $\mathrm{S}$ AOIs are identified as less stressed areas while $\mathrm{C} 1$ and $\mathrm{C} 2 \mathrm{AOIs}$ show the lower average NDVI values.

\begin{tabular}{ccccc}
\hline \multirow{2}{*}{ AOI } & \multicolumn{2}{c}{ NDVI_A11 } & \multicolumn{2}{c}{ NDVI_W11 } \\
\cline { 2 - 5 } & $\begin{array}{c}\mathbf{N}^{\circ} \\
\text { pixel }\end{array}$ & Mean/St. Dev. & $\begin{array}{c}\mathbf{N}^{\circ} \\
\text { pixel }\end{array}$ & $\begin{array}{c}\text { Mean/St. } \\
\text { Dev. }\end{array}$ \\
\hline N & 2029 & $0.811 / 0.025$ & 114826 & $0.831 / 0.048$ \\
\hline C1 & 1239 & $0.763 / 0.030$ & 70271 & $0.788 / 0.046$ \\
\hline C2 & 551 & $0.773 / 0.024$ & 22908 & $0.819 / 0.029$ \\
\hline S & 3104 & $0.809 / 0.033$ & 176248 & $0.832 / 0.055$ \\
\hline
\end{tabular}

Table 1. Basic statistics of NDVI values

To evaluate the difference between results shown in Table 1 the Student t-test was applied.

Given N, C1, C2, S AOIs, the sample consisted of the NDVI values for the two data. Due to the different resolution, the largeness of samples differed by one or two orders of magnitude. Moreover, the element number of the samples was elevated. The results reported in Table 2 show that the NDVI averages are significantly different for each AOI. In fact, the NDVI differences exceeded the limit $t_{\alpha}=3.3$ corresponding to the significance level of $\alpha=0.1 \%$ conservatively assumed for the test.

\begin{tabular}{|c|c|c|}
\hline AOI & $\mathbf{t}$ & $\boldsymbol{v}$ \\
\hline $\mathbf{N}$ & $\mathbf{3 4 . 9}$ & 2300.6 \\
\hline $\mathbf{S}$ & $\mathbf{3 7 . 9}$ & 3413.9 \\
\hline $\mathbf{C 2}$ & $\mathbf{6 6 . 6}$ & 1302.5 \\
\hline $\mathbf{C 1}$ & $\mathbf{1 9 . 0}$ & 613.9 \\
\hline
\end{tabular}

Table 2. Student $t$-test results relative to the average NDVI differences
The real distribution of NDVI_A11 and NDVIW11 values were analyzed by relative frequency histograms shown in Fig.4. Regarding the NDVI_A11 graphs, it is possible to distinguish three different histogram shapes related to several AOI behaviors. The most stressed area has a right tail, while the healthiest shows a left tail. The intermediate area does not show any tail. Instead, from the NDVI_W11 graphs is less evident the presence of tail, but $\mathrm{S}$ and $\mathrm{C} 1$ AOIs show a bimodal trend and, probably due to the different vegetation species present in TDF. In the histograms, the grey line represents the NDVI value corresponding to the 5th percentile computed in the AOI with the highest average NDVI value, i.e. the $\mathrm{N}$ area for ASTER image (0.767) and the $S$ area for in the WV-2 data (0.742). For each data, the percentage of pixels below this limit was calculated for the remaining AOIs (Tab. 3). For the NDVI_A11, the percentages of pixels below the limit increases moving from the areas with higher average NDVI values ( $\mathrm{N}$ and $\mathrm{S}$ ) towards the lower NDVI values ( $\mathrm{C} 1$ and $\mathrm{C} 2)$.

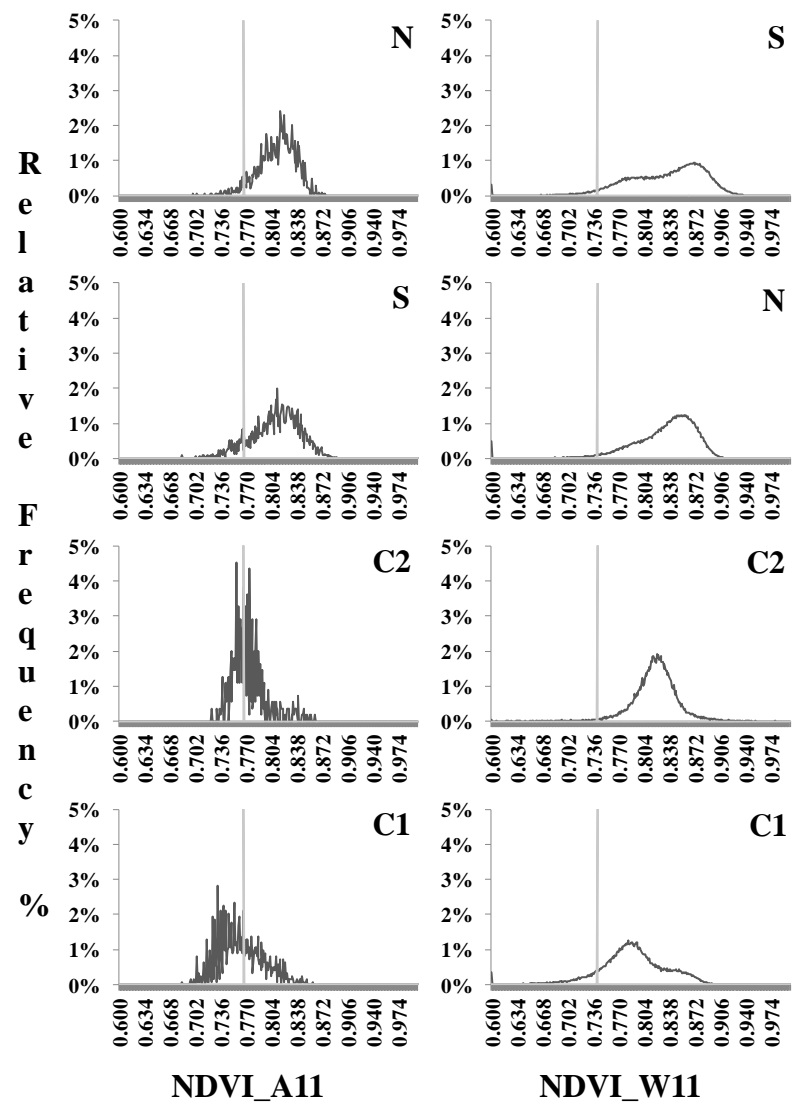

Figure 4. Relative frequency histograms of NDVI values. Based on average NDVI the AOIs are reported in descending order

This behaviour is less evident in the NDVI_W11 histograms where the worst area $(\mathrm{C} 2)$ has only $12 \%$ of pixel below the threshold.

\begin{tabular}{|c|c|c|c|c|c|}
\hline & & \multicolumn{4}{|c|}{ \% pixels of stressed vegetation } \\
\hline & Threshold & N & S & C1 & C2 \\
\hline NDVI_A11 & N: $\mathbf{0 . 7 6 7}$ & 5.00 & 11.60 & 59.00 & 47.60 \\
\hline NDVI_W11 & S: 0.742 & 3.40 & 5.00 & 12.00 & 1.20 \\
\hline
\end{tabular}

Table 3. Percentage of pixels below the threshold determined on the AOI with higher average NDVI value 
Additional information can be obtained by studying the Skewness and Kurtosis shape factors (Tab. 4).The NDVI_A11 Skewness results confirm that the $\mathrm{N}$ and $\mathrm{S}$ areas have a left tail, whereas $\mathrm{C} 2$ have a right tail.

\begin{tabular}{|c|c|c|c|}
\hline AOI & Shape Factors & NDVI_A11 & NDVI_W11 \\
\hline \multirow{2}{*}{$\mathbf{N}$} & Skewness & -0.594 & -2.640 \\
\hline & Kurtosis & 0.528 & 15.474 \\
\hline \multirow{2}{*}{ C1 } & Skewness & 0.432 & -0.847 \\
\hline & Kurtosis & -0.153 & 3.784 \\
\hline \multirow{2}{*}{$\mathrm{C2}$} & Skewness & 1.194 & -0.641 \\
\hline & Kurtosis & 1.752 & 5.090 \\
\hline \multirow{2}{*}{$\mathbf{S}$} & Skewness & -0.466 & -1.253 \\
\hline & Kurtosis & 0.079 & 4.547 \\
\hline
\end{tabular}

Table 4. Higher order moment results

With regard to the NDVI_A11 Kurtosis results, they are close to zero, with the $\mathrm{C} 1$ factor negative, demonstrating that their value distribution get closer the Gaussian distribution. Instead, the NDVI_W11 Skewness results are negative for all AOIs and $\mathrm{S}$ and $\mathrm{N}$ have the longest tail. Finally, all the Kurtosis values are largely positive showing that their NDVI value distributions moves away from Gaussian due to more acute peaks around the mean.

The following rankings were derived from the previous results (Tab.5). Based on the average NDVI the AOIs are reported in descending order.

\begin{tabular}{|c|c|c|}
\hline Order & NDVI_A11 & NDVI_W11 \\
\hline $\mathbf{1}$ & N & S \\
\hline $\mathbf{2}$ & S & N \\
\hline $\mathbf{3}$ & C 2 & C 2 \\
\hline $\mathbf{4}$ & C 1 & C 1 \\
\hline
\end{tabular}

Table 5. ASTER and WV-2 AOI ranking based on average NDVI values.

Table 5 shows that both satellite data recognize as the more suffering areas the AOIs located between two drainage channel crossing the pine forest, i.e. $\mathrm{C} 1$ and $\mathrm{C} 2$. However, areas $\mathrm{N}$ and $\mathrm{S}$ are inverted in the two rankings. Therefore, in order to assess if the difference between $\mathrm{N}$ and $\mathrm{S}$ average NVDI values could be considered negligible, the previous Student t-test was separately applied on each satellite data. From Table 1, it is possible to deduce that the difference between $\mathrm{N}$ and $\mathrm{S}$ average NDVI values in absolute terms is of 0.002 for NDVI_A11 and of 0.001 for NDVI_W11.

\begin{tabular}{|c|c|}
\hline & t \\
\hline N-S NDVI_A11 & 2.5 \\
\hline N-S NDVI_W11 & -5.2 \\
\hline
\end{tabular}

Table 6. Student t-test results relative to the $\mathrm{N}$ and $\mathrm{S}$ average NDVI differences for each image.

For the Aster data, the test result is lower than the limit $\mathrm{t}_{\alpha}=3.3$ corresponding to the significance level of $\alpha=0.1 \%$ assumed for the test. Instead, for the WV-2 image the equality hypothesis between the two average NDVI values is not acceptable (Tab. 6). The problem is probably related to the large amount of data that, reducing the standard deviation in the denominator, raises the relationship value.

\subsection{ASTER and resampled WV-2 comparison}

After the WV-2 pixels resampling and re-projection to the ASTER projection and pixel size $(15 \mathrm{~m})$, the new AOI average NDVI values were equal to the average NDVI values of noresampled WV-2 AOIs (Tab. 7).

\begin{tabular}{|c|c|c|c|}
\hline \multicolumn{4}{|c|}{ Resampled WV-2 } \\
\hline AOI & $\mathbf{N}^{\circ}$ pixel & Mean & Dev. St \\
\hline $\mathbf{N}$ & 2029 & 0.8323 & 0.0494 \\
\hline S & 3104 & 0.8316 & 0.0541 \\
\hline C1 & 1239 & 0.7879 & 0.0299 \\
\hline C2 & 551 & 0.8199 & 0.0161 \\
\hline
\end{tabular}

Table 7.Basic statistics of NDVI values for the resampled WV-2

In this case, the result of the Student $t$-test $(t=0.5)$ applied on the new $\mathrm{N}$ and $\mathrm{S}$ average NDVI difference demonstrated that the new NDVI averages of the two WV-2 AOIs could be considered equal. Therefore the previous AOI rankings obtained from the two sensors can be considered coincident.

The availability of NDVI values comparable between ASTER and WV-2 allowed the pixel to pixel correlation between the all AOI pixels of NDVI_A11 and all AOI pixels of resampled NDVI_W11 (Fig. 5). The graph shows that the limited NDVI_A11 range of variability $(0.683-0.890)$ corresponds to a very large range of values assumed by NDVI_W11 $(0.283-$ 0.992). The likely cause is the original WV-2 high spatial resolution that makes the satellite data more sensitive to the vegetation variability within the TDF class. However, the global regression line coefficient is high, almost 0.84 demonstrating a good correlation between the two satellite images.

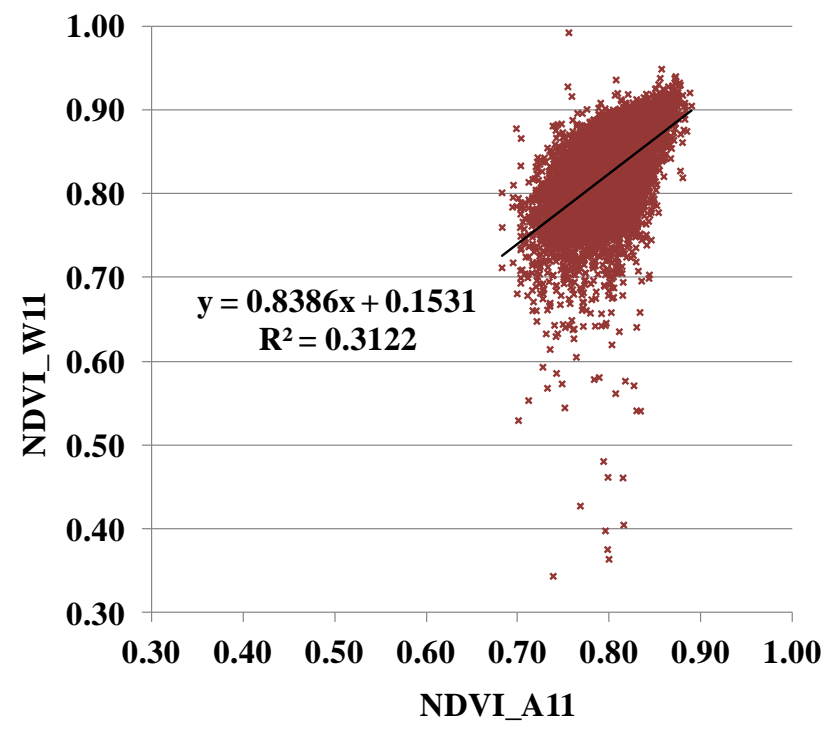

Figure 5. Pixel to pixel correlation between the all AOI pixels of NDVI_A11 and the all AOI pixels of resampled NDVI_W11.

However, the single AOI behavior is different. While for the pixel to pixel linear correlations of $\mathrm{N}, \mathrm{S}$ and $\mathrm{C} 1$ areas the angular coefficient ranges from 0.71 to 0.99 , the $\mathrm{C} 2$ coefficient (0.2) proves the almost total invariance of the NDVI_W11 compared to NDVI_A11. This anomalous behavior is evident also in Fig.6. The graph shows the relationship between the average NDVI_W11 AOI values and the average NDVI_A11 AOI values. The error bars are a graphical representation of the standard deviations of each average value while the red line is 
the regression line relative to $\mathrm{N}, \mathrm{S}$ and $\mathrm{C} 1$ values. The linear correlation between the average NDVI values of these areas is remarkable, instead the $\mathrm{C} 2$ behavior, excluded from the calculation, differs greatly. For comparison, the bisector indicated by the dashed line was reported.

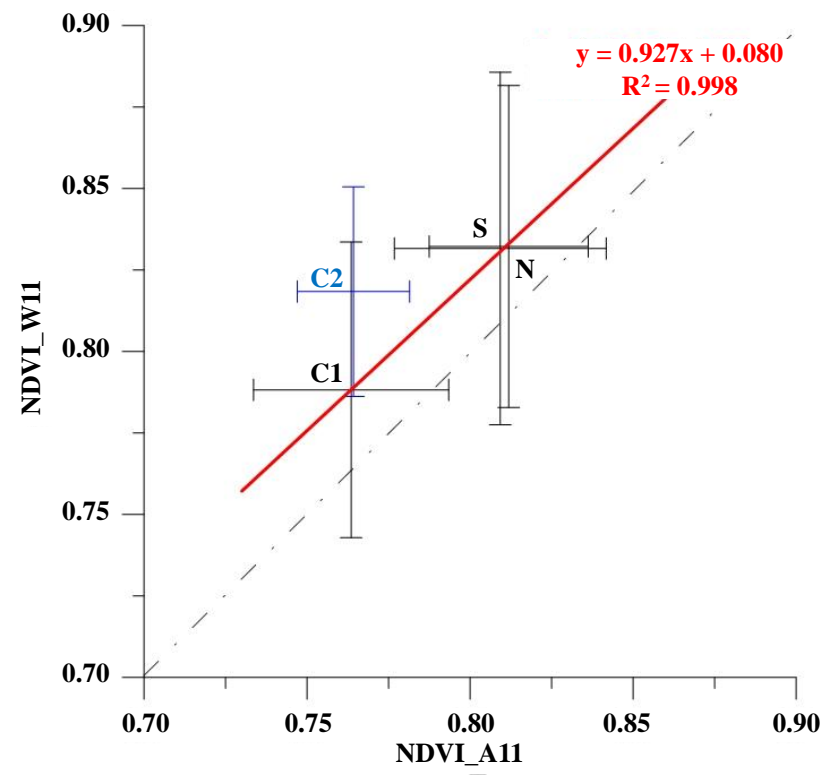

Figure 6. Relationship between the average NDVI_W11 AOI values and the average NDVI_A11 AOIs values

\subsection{Result validation by groundwater salinity data}

Despite the different spatial resolution that implies a different response at individual pixel level, both satellite data provided the same AOI ranking, recognizing $\mathrm{N}$ and $\mathrm{S}$ areas as the areas covered by healthier vegetation while $\mathrm{C} 1$ and $\mathrm{C} 2$ those covered by more suffering vegetation.

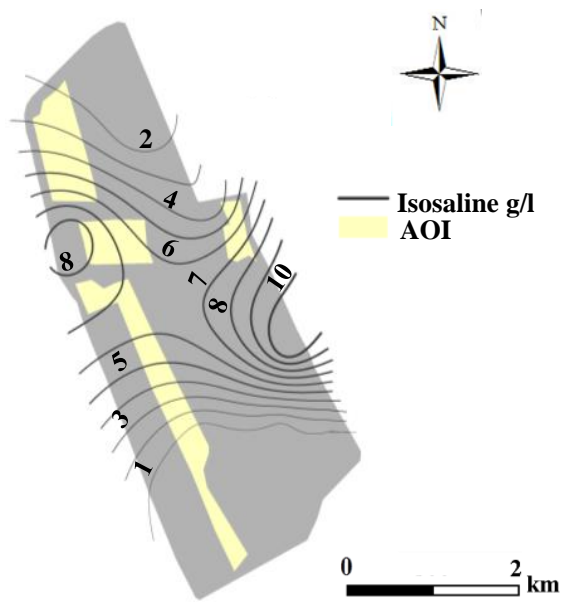

Figure 7. Overlay between the Classe AOI locations and the groundwater salinity isosalines ( $\mathrm{g} / \mathrm{l})$ of May 2011

These findings were validated by the contemporaneous groundwater salinity data. Figure 7 shows the spatial salinity distributions relative to May 2011 through the isosaline.
The AOIs characterized by higher salinity (from 5 to $8 \mathrm{~g} / \mathrm{l}$ ) were $\mathrm{C} 1$ and $\mathrm{C} 2$ while a wider salinity variability range involved the remaining AOIs. Everywhere in the pine forest the surface salinity is below $12 \mathrm{~g} / \mathrm{l}$. The mean and the standard deviation salinity values extracted for each AOI are reported in Tab. 9. The maxinum average salinity value for May 2011 was recorded within the $\mathrm{C} 1$ area $(6.94 \mathrm{~g} / \mathrm{l})$ whereas $\mathrm{S}$ and $\mathrm{N}$ had the lower average salinity values, respectively, 3.46 and $3.94 \mathrm{~g} / \mathrm{l}$.

\begin{tabular}{|c|c|c|c|}
\hline \multicolumn{4}{|c|}{ Salinity(g/l) } \\
\hline AOI & $\mathbf{N}^{\circ}$ pixel & Mean (g/l) & Dev. St \\
\hline $\mathbf{N}$ & 2029 & 3.94 & 1.27 \\
\hline C1 & 1239 & 6.94 & 0.77 \\
\hline C2 & 3104 & 5.99 & 0.95 \\
\hline S & 551 & 3.46 & 2.84 \\
\hline
\end{tabular}

Table 9. Basic statistics of salinity values of the Classe AOIs

For every satellite data, the relationship between the average salinity and NDVI values of each AOI were verified (Fig. 8 and Fig. 9). Taking into account that the salinity standard deviations were highly variable between the AOIs while the NDVI standard deviations were comparable from sample to sample, within each satellite data, the Equation 6 was applied.

The slope of the regression line is negative for both considered images, confirming the relation between lower NDVI and higher salinity values and vice versa.

However, the variability range of the NDVI_W11 regression line slope is wider than that of NDVI_A11.

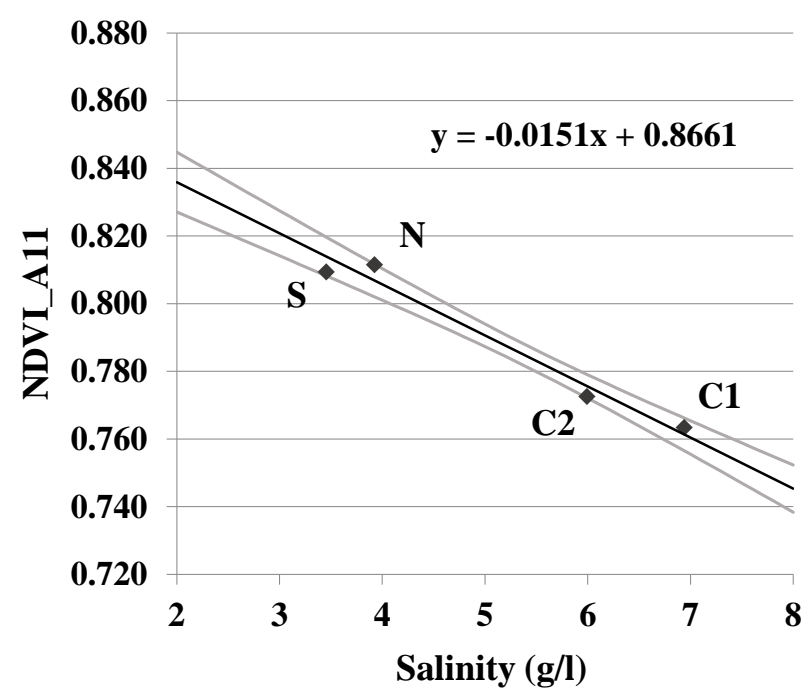

Figure 8. Correlation between the average NDVI_A11 and groundwater salinity values for Classe AOIs

Finally, after all the assessments made, a comparison of the AOI rankings in terms of NDVI_A11, NDVI_W11 and groundwater salinity data can be done. Table 10 shows a perfect agreement between the results obtained.

In particular, the most stressed areas $(\mathrm{C} 1$ and 22$)$ are located in the portion of pinewood define by the two drainage channels. This consideration agree with the findings of Antonellini et al., (2008) who identify drainage channels as accountable of vertical seepage of saline water from the bottom part of the aquifer. 


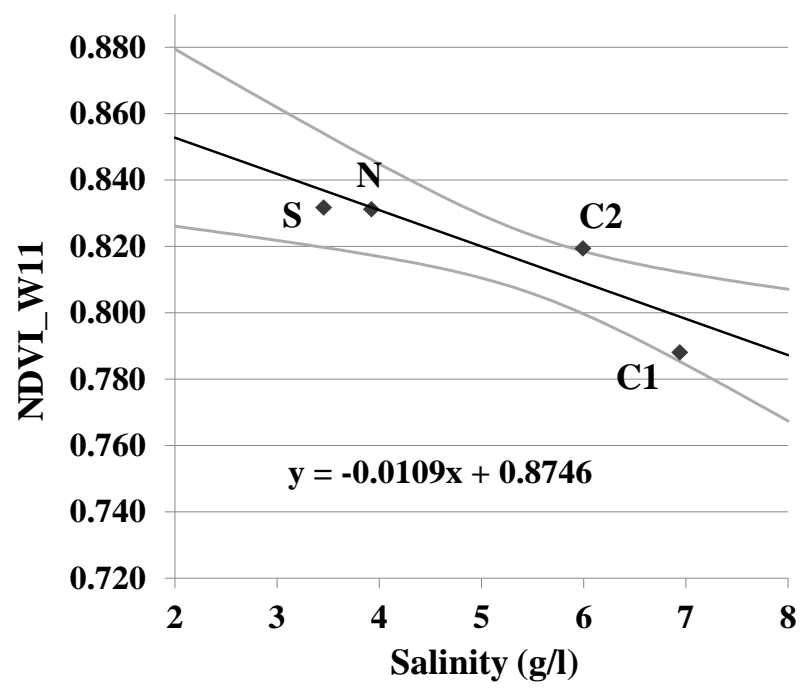

Figure 9. Correlation between the average NDVI_W11 and groundwater salinity values for Classe AOIs

\begin{tabular}{|c|c|c|}
\hline Order & NDVI_A11/W11 & Salinity \\
\hline $\mathbf{1}$ & $\mathrm{S}$ & $\mathrm{S}$ \\
\hline $\mathbf{2}$ & $\mathrm{N}$ & $\mathrm{N}$ \\
\hline $\mathbf{3}$ & $\mathrm{C} 2$ & $\mathrm{C} 2$ \\
\hline $\mathbf{4}$ & $\mathrm{C} 1$ & $\mathrm{C} 1$ \\
\hline
\end{tabular}

Table 10. Comparison between the rankings of AOIs in terms of NDVIs and salinity. The AOIs are reported in descending order.

\section{CONCLUSIONS}

The same NDVI ranking has been obtained considering both satellite datasets keeping the original spatial resolution, unless the areas $\mathrm{N}$ and $\mathrm{S}$ which are inverted. However the Student $\mathrm{t}-$ test reveals that the average AOIs NDVI calculated from ASTER data is statistically different from the average AOIs NDVI calculated from WV-2 data. The same test repeated to assess if the difference between the average NDVI values of $\mathrm{N}$ and $\mathrm{S}$ shows a significant difference for WV-2 image. For ASTER image the histogram analysis identifies the left tails for the less stressed AOIs and right tails for the most stressed; this different shape is less evident for WV-2 data. In the same way the percentage of pixels below the 5\% threshold can be used as measure of stress conditions only for ASTER image; in fact for WV image the percentage of pixels are not related with the average AOIs NDVI.

After the WV re-sampling and re-projection to the ASTER resolution, the ranking was the same and the statistical evaluation of $\mathrm{N}$ and $\mathrm{S}$ average NDVI revealed that can be considered equal. The correlation between ASTER and resampled WV-2 shows high values for the regression line coefficients which considerably improve using the average AOIs NDVI, excluding C2. From the validation with the groundwater salinity emerges that the previous AOIs ranking based on average NDVI perfectly agree with the ranking of salinity, i.e. $\mathrm{N}$ and $\mathrm{S}$ AOIs have the lower average salinity and the higher NDVI values while the contrary for C1and C2. Finally, the use of the NDVI analysis allowed to identify the AOIs more affected by groundwater salinization based on the groundwater monitoring data. The same NDVI ranking has been obtained considering either by keeping the original spatial resolution of the satellite data that with the WV-2 re-sampling and re-projection. After these findings is possible to conclude that ASTER and WV-2 sources can be integrated with the aim to study environmental problems which require a long dataset even back in time.

\section{ACKNOWLEDGEMENTS}

A special thanks to Prof. Giovanni Gabbianelli for having made available the WorldView-2 data and for the constant supervision to the work.

\section{REFERENCES}

Abuzar, M., Sheffield, K., Whitfield, D., O'Connell, M., McAllister, A., 2014. Comparing inter-sensor NDVI for the analysis of horticulture crops in south-eastern Australia. American Journal of Remote Sensing, 2(1), pp.1-9.

Aguilar, C., Zinnertb, J.C., Poloa, M.R., Young, D.R., 2012. NDVI as an indicator for changes in water availability to woody vegetation. Ecological Indicators, 23, pp. 290-300.

Akkala, A., Devabhaktuni, V., \& Kumar, A., 2010. Interpolation techniques and associated software for environmental data. Environmental progress \& sustainable energy, 29 (2), pp. 134-141.

Amorosi, A., Colalongo, M.L., Pasini, G., Preti, D., 1999. Sedimentary response to Late Quaternary sea-level changes in the Romagna coastal plain (northern Italy). Sedimentology, 46(1), pp. 99-121.

Antonellini, M., Mollena, P., Giambastiani, B.M.S., Bishop, K., Caruso, L., Minchio, A., Pellegrini, L., Sabia, M., Ulazzi, E., Gabbianelli, G., 2008. Salt water intrusion in the coastal aquifer of southern Po Plain, Italy. Hydrogeology journal, 16, pp.1541-1556.

Antonellini, M., Mollema, P., 2010. Impact Of Groundwater Salinity On Vegetation Species Richness In The Coastal Pine Forests And Wetlands Of Ravenna, Italy. Ecological Engineering, 236(9), pp. 1201-1211.

Bailey, G. B., Lauer, D. T., Carneggie, D. M., 2001. International collaboration: the cornerstone of satellite land remote sensing in the 21st century. Space Policy, 17(3), pp. 161-169.

Barbarella, M., De Giglio, M., Greggio, N., 2015. Effects of salt water intrusion on pinewood vegetation using satellite ASTER data: the case study of Ravenna (Italy). Environmental Monitoring and Assessment. DOI: 10.1007/s10661-015-4375-z.

Barton, C.WM., 2012. Advances in remote sensing of plant stress. Plant and Soil, 354, pp. 41-44.

Buscaroli, A., Zannoni, D., 2010. Influence of ground water on soil salinity in the San Vitale Pinewood (Ravenna-Italy). Agrochimica, 54(5), pp. 303-320

Chander, G., Coan, M. J., Scaramuzza, P. L., 2008. Evaluation and comparison of the IRS-P6 and the Landsat sensors. Geoscience and Remote Sensing, IEEE Transactions on, 46(1), pp. 209-221.

Dehaan, R. L., Taylor, G. R., 2002. Field-derived spectra of salinized soils and vegetation as indicators of irrigation-induced 
soil salinization. Remote Sensing of Environment, 80(3), pp. 406-417.

DeLaune, R.D., Pezeshki, S.R., Patrick Jr., W.A., 1987. Response of coastal plants to increase in submergence and salinity. Journal of Coastal Research, 3(4), pp. 535-546.

FLAASH Module, 2009. Atmospheric Correction Module: QUAC and FLAASH User's Guide, ENVI Version 5.0. ITT Visual Information Solutions, Boulder, CO.

Ginanni, F., 1774. Istoria civile e naturale delle Pinete Ravennati nella quale si tratta della loro origine, situazione, fabriche antiche, e moderne, terre moltiplici, acqua, aria, fossili, vegetabili, \&c: Opera postuma. Generoso Salomoni.

Giorgi, F., Lionello, P. (2008). Climate Change Projections For The Mediterranean Region. Global Planet Change, 63, pp. 90104.

Naumann, J.C., Anderson, J.E., Young, D.R., 2008. Linking physiological responses, chlorophyll fluorescence and hyperspectral imagery to detect salinity stress using the physiological reflectance index in the coastal shrub, Myrica cerifera. Remote sensing of environment, 112(10), pp. 38653875 .

Peñuelas, J., 1998. Visible and near-infrared reflectance techniques for diagnosing plant physiological status. Trends in Plant Science, 3, pp. 151-6.

Piccoli, F., Gerdol, R., Ferrari, C., 1991. Vegetation Map of St. Vitale pinewood (Northern Adriatic coast, Italy). Phytocoenosis, pp. 337-342.

Pu, R.; Landry, S., 2012. A comparative analysis of high spatial resolution IKONOS and WorldView-2 imagery for mapping urban tree species. Remote Sens. Environ., 124: pp. 516-533

Reed, B.C., Brown, J.F., Vander Zee, D., Loveland, T.R., Merchant, J.W., Ohlen, D.O., 1994. Measuring phenological variability from satellite imagery. Journal of Vegetation Science, 5, pp. 703-714.

Regione Emilia Romagna - Servizio Cartografico e Geologico, 1999. Carta della Vegetazione del Parco Regionale del Delta del Po - Stazione "Pineta di Classe e Saline di Cervia". http://geoportale.regione.emilia-romagna.it/it/catalogo/daticartografici/ambiente/carta-della-vegetazione/carta-dellavegetazione-parco-regionale-del-delta-del-po-stazione-pinetadi-classe-e-saline-di-cervia-digitale-edizione-1999. Accessed $02 / 22 / 2015$

Thenkabail, P. S. 2004. Inter-sensor relationships between IKONOS and Landsat-7 ETM+ NDVI data in three ecoregions of Africa. International Journal of Remote Sensing, 25(2), 389408 .

Tilley, D.R., Ahmed, M., Son, J.H., Badrinarayanan, H., 2007. Hyperspectral reflectance response of freshwater macrophytes to salinity in a brackish subtropical marsh. Journal of Environmental Quality, 36, pp. 780-789.

UNESCO, 1983. Algorithms for computation of fundamental properties of seawater. Unesco technical papers in marine science 44, Unesco/SCOR/ICES/IAPSO Joint Panel on
Oceanographic Tables and Standards and SCOR Working Group 51 .

Wald, L., Ranchin, T., Mangolini, M., 1997. Fusion of satellite images of different spatial resolutions: assessing the quality of resulting images. Photogrammetric Engineering and Remote Sensing, 63(6), pp. 691-699.

Wiegand, C.L., Rhoades, J.D., Escobar, D.E., Everitt, J.H., 1994. Photographic and videographic observations for determining and mapping the response of cotton to soil-salinity. Remote Sensing of Environment, 49, pp. 212-223.

Yin, H., Udelhoven, T., Fensholt, R., Pflugmacher, D., Hostert, P., 2012. How normalized difference vegetation index (ndvi) trendsfrom advanced very high resolution radiometer (AVHRR) and système probatoire d'observation de la terre vegetation (spot vgt) time series differ in agricultural areas: An inner mongolian case study. Remote Sensing, 4(11), pp. 3364-3389.

Yuan, J., Niu, Z., 2008. Evaluation of atmospheric correction using FLAASH. In: International Workshop on Earth Observation and Remote Sensing Applications, pp. 1-6.

Zhang, T., Zeng, S.L., Gao, Y., Ouyang, Z.T., Li, B., Fang, C.M., Zhao, B., 2011. Using hyperspectral vegetation indices as a proxy to monitor soil salinity. Ecological Indicators, 11, $1552-1562$. 